Moreno-Ospina, J. (2019). Patrimonio industrial en Tunja. Memorias de crecimiento. Revista de Antropología y Sociología: VIRAJES, 21(2), 81-101. DOI: 10.17151/rasv.2019.21.2.5

\title{
Patrimonio industrial en Tunja. Memorias de crecimiento
}

JAIRO MORENO-OSPINA**

Recibido: 11 de febrero de 2019

Aprobado: 29 de abril de 2019

Artículo de reflexión

\footnotetext{
* Docente de la Licenciatura en Artes Plásticas de la UPTC. Estudiante de Maestría en Patrimonio Cultural. Universidad Pedagógica y Tecnológica de Colombia, Tunja, Boyacá, Colombia. E-mail: jairo. moreno@uptc.edu.co. () ORCID: 0000-0002-4876-4830. Google Scholar
} 


\title{
Resumen
}

El artículo ofrece experiencias y vivencias de Tunja, en relación con los rastros industriales (algunos intangibles, ya desaparecidos), pero en especial con los del sector norte de la ciudad, que desde mediados del siglo pasado se constituyeron en un núcleo industrial que incidió fuertemente en el desarrollo de la ciudad. Cinco empresas conformaron esta área que en su momento, estando muy separadas del centro histórico de Tunja, fueron dejando de funcionar al terminar el siglo XX. Cada una de ellas, aún con rastros arquitectónicos particulares ligados a su función y que en el presente han cambiado su uso, se encuentran en ruinas o simplemente desaparecieron. Se realizan recorridos, conversaciones y observaciones que permiten detectar cómo el espíritu del trabajo pervive de otras formas en este territorio. Finalmente, se reflexiona sobre cómo este tipo de recorridos, desde una perspectiva patrimonial actúa como provocador de experiencias artísticas fortaleciéndose en este sentido.

Palabras clave: patrimonio industrial, Tunja - siglo XX, Tunja - patrimonio, patrimonio y arte, Tunja.

\section{Industrial Heritage in Tunja. Development memories}

\begin{abstract}
The article offers experiences and life lessons of Tunja in relation to industrial traces (some of them intangible or already disappeared) but especially with those of the northern sector of the city, which, since the middle of the last century became an industrial nucleus that strongly influenced the development of the city. Five companies formed this area that, at the time, being away from the historical center of the city, ceased functioning at the end of the 20th century. Each one of them, even with particular architectural traces linked to their function, and that in the present have changed their use, are in ruins or have simply disappeared. Tours, conversations and observations are made to detect how the spirit of work survives in other ways in this territory. Finally, it is possible to reflect on how this type of tours, from a heritage perspective, acts as a provocative agent for artistic experiences, strengthening in this sense.
\end{abstract}

Key words: industrial heritage, Tunja - 20th century, Tunja- heritage, heritage and art, Tunja. 


\section{Introducción}

manece. A medida quela ciudad despierta, va desvaneciéndose
en el aire un manto de niebla que nace en los humedales y los
cubre la mayor parte del año. En la segunda mitad del siglo pasado, el manto persistía todo el día, era diferente, seguía siendo blanco, pero se sentía pesado y no desaparecía, nacía en grandes y ruidosas naves. Se instalaba cubriendo las casas, las carreteras, los árboles y los obreros. Todo se teñía de una sombra blanca constante. Ahora, las naves han quedado silenciosas. Los humedales siguen ese rumbo, se van perdiendo. La niebla pesada ya no está. La otra, la del origen de las nubes, insiste en amanecer allí.

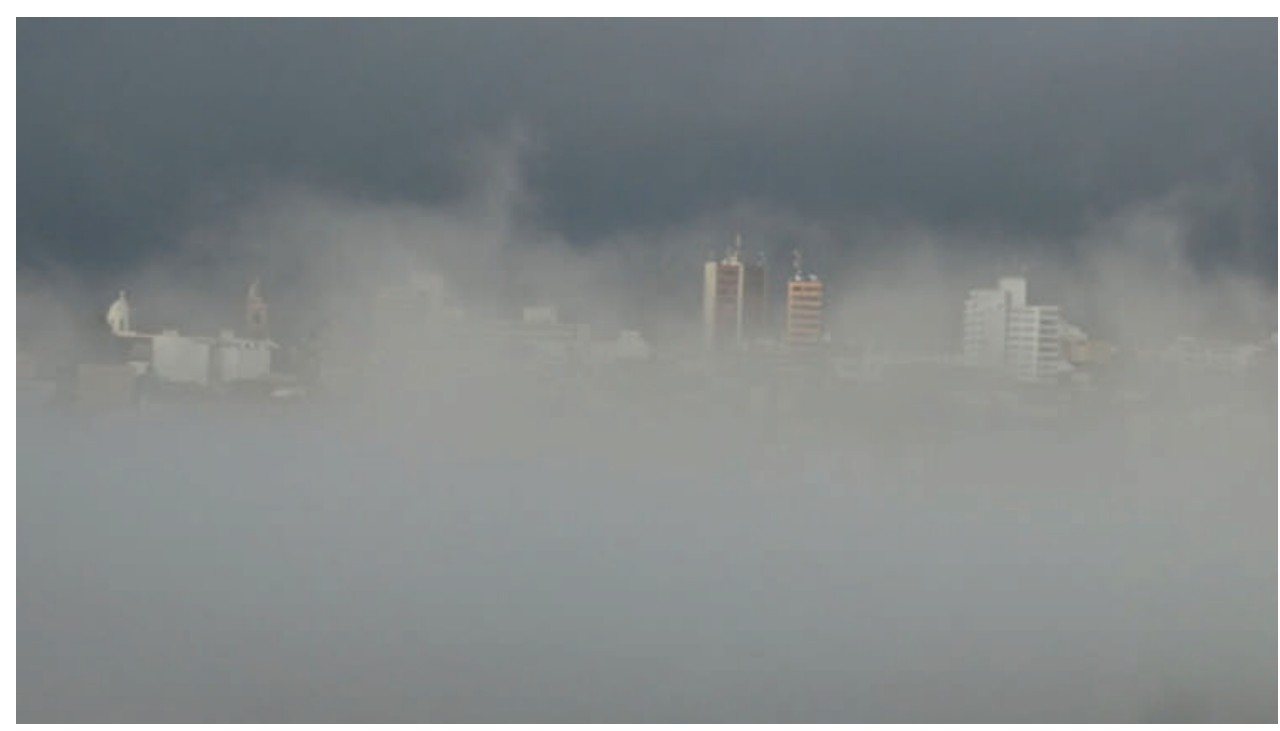

Imagen 1. Amanecer en Tunja. Fuente: Autor (2016)

Cuando se es oriundo de una ciudad y la mayor parte de la vida ha transcurrido en ella, se es testigo de sus transformaciones. La Tunja de mi infancia era pequeña; vivía en un barrio de la periferia, a diez cuadras del centro y se puede decir que era la misma distancia hacia cualquier borde de la pequeña ciudad. Años después, inevitablemente, Tunja empezó a extenderse hacia el norte y hacia el sur, con una apariencia algo alargada, situación dada por las condiciones geográficas que dificultaban su crecimiento hacia los laterales. 
La ciudad está cerca de cumplir 500 años de su fundación española $\mathrm{y}$, como todas las principales ciudades que tuvieron su origen en ese momento, fue instalada sobre un asentamiento indígena. El zaque de los muiscas de este territorio poseía un cercado y la población se instalaba en viviendas esparcidas en una ladera bordeada por dos ríos ${ }^{1}$ : Farfacá por el occidente y Funsi por el oriente. Los muiscas no alcanzaron a desarrollar una arquitectura lítica como los aztecas o los incas, para quedar así solamente, rastros ceremoniales: los Cojines del Zaque, las Moyas de San Ricardo, el Pozo de Hunzahúa, lugares que marcaban mi límite del mundo que ahora la urbe absorbió. Esos sitios eran los destinos de los paseos familiares.

Con la llegada de los españoles las viviendas muiscas desaparecieron, en su lugar se levantaron construcciones en adobe y teja: edificaciones ortogonales, pegadas unas a otras, las calles rectas, un orden diferente del espacio, del territorio y de sus gentes. La ciudad se hizo consentida por los nuevos y lejanos dueños, floreció brevemente, se levantaron inmensas casonas de exteriores lisos, sobrios, cubiertos de cal. Unas sagradas donde habitaban Dios y sus santos, en su interior retablos del piso al techo, cubiertos de oro y personajes policromados de expresiones dolorosas. Las otras con interiores adornados con representaciones de plantas y animales nunca vistos. Casi fue la capital del Nuevo Reino. Todo se estancó, se llenó de rezanderos, una iglesia en cada cuadra. Un espejo de eso que Calvino (1999) expresa bellamente en Las ciudades invisibles:

Hay que cuidarse de decirles que a veces ciudades diferentes se suceden sobre el mismo suelo y bajo el mismo nombre, nacen y mueren sin haberse conocido, incomunicables entre sí. En ocasiones hasta los nombres de los habitantes permanecen iguales, y el acento de las voces, e incluso las facciones; pero los dioses que habitan bajo esos nombres y en esos lugares se han ido sin decir nada y en su sitio han anidado dioses extranjeros. Es inútil preguntarse si estos son mejores o peores que los antiguos, dado que no existe entre ellos ninguna relación, así como las viejas postales no representan a Maurilia como era, sino a otra ciudad que por casualidad se llamaba Maurilia como ésta. (p. 34)

El haber sido consentida en la Colonia le salió caro a Tunja en la época Republicana; olvidada, la antítesis de lo que debería ser un lugar

\footnotetext{
${ }^{1}$ Los nombres Farfacá y Funsi pertenecen a los del periodo precolombino, en la Colonia el río Farfacá tomaría el nombre de La Vega y el río Funsi el de Jordán.
} 
independiente ${ }^{2}$. Ya bien entrado el siglo XX, despierta muy despacio. El ingreso de la República trae nuevos estilos arquitectónicos con fuertes influencias inglesas y francesas que se instalan especialmente en las construcciones gubernamentales como en la desaparecida alcaldía y en la gobernación. Posteriormente, aparecen tendencias art déco en la antigua oficina de teléfonos y en el teatro cultural, tendencia que tuvo buena influencia en las fachadas de las casas populares. Todo ocurría en lo que es hoy el centro histórico de una ciudad que poco se extendía.

Al norte, alejado del casco urbano, un territorio, un paisaje particular. Unos 300 metros adelante del Pozo de Hunzahúa, los ríos tutelares de la ciudad se unen y siguen su curso hacia el norte, unos kilómetros después tomarán el nombre de río Chicamocha, que va en búsqueda del río Magdalena. Allí se conforma un terreno plano y firme, que hasta mediados del siglo pasado hizo parte de las haciendas allí constituidas. En este empezaron a levantarse construcciones diferentes a las acostumbradas, con otras técnicas y otros materiales; inmensos cascarones, en los que no habitaban gentes sino ruidosas máquinas, estructuras metálicas cubiertas de láminas de metal o de cemento, que ya no ocultaban sus ensambles y uniones, tornillos y argamasas que quedaban a la vista.

Fue un periodo muy corto y cercano en el tiempo. En menos de medio siglo este particular sector se conformó y se desvaneció. Ya a finales del año 2000 había perdido la característica que lo constituyó: la industria. Quedaron los cascarones gigantescos que resguardaban los procesos mecanizados que se daban en su interior y que habían dejado de operar. Ahora es un paisaje conformado por un espacio donde funcionaron unas empresas que en su conjunto harían pensar en el esbozo de un parque industrial: la Estación del Ferrocarril, la subestación de energía de la Electrificadora de Boyacá, los silos del IDEMA, Ferroaleaciones de Colombia y Caolines Boyacá. En este corto tiempo, se instauró como un polo de desarrollo hacia el norte de la ciudad, tanto por la oferta de trabajos, como por el crecimiento de los barrios vecinos, el empuje urbano hacia el norte y la ampliación de las vías terrestres.

Esta segunda parte del siglo XX pasa desapercibida tanto en la historia oficial tunjana, como en el imaginario de su gente. Es necesario volver la mirada ya que su incidencia en el desarrollo de la ciudad fue importante, marchó como una fuerza que impulsó, expandió y transformó

\footnotetext{
${ }^{2}$ Manuel Ancízar (1812-1882) hizo parte de la comisión corográfica (1850-1862) encargada de hacer un profundo estudio de país, de entenderlo desde diversas perspectivas. En su descripción de Tunja deja ver un desdén al describirla como un lugar frío, detenido en el tiempo donde pervivían las costumbres españolas.
} 
este territorio. Las construcciones van desapareciendo..., el patrimonio industrial ha permitido realizar en otros lugares el rescate y salvaguardar los rastros que implicaron en un momento espacios vitales para la población, los ha reactivado y los ha documentado, siendo esta otra forma en la que el recuerdo encuentra dónde revivirse, convirtiéndose así en la intención principal de la escritura de este texto.

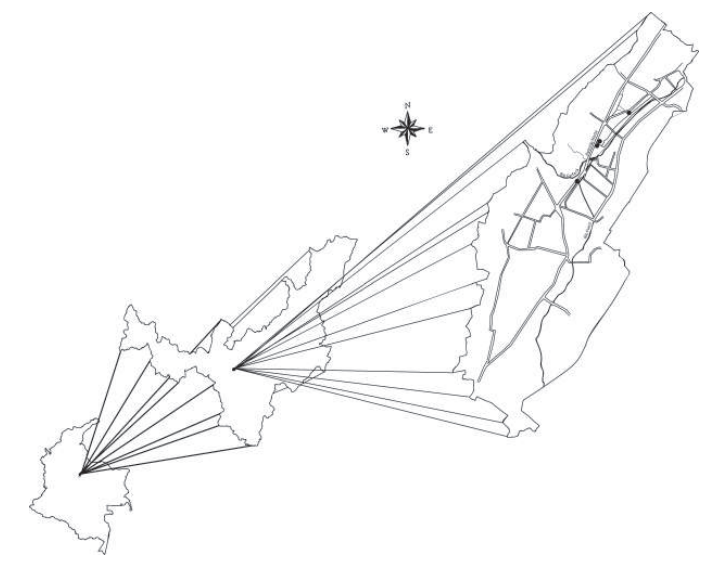

Imagen 2. Cartografía general. Fuente: Jeikson Orjuela (2018)

\section{La industria se instala. Un paisaje posindustrial}

Hubo dos sonidos en Tunja que marcaban el ritmo de la ciudad: una sirena que se escuchaba hasta en el último rincón, anunciaba la entrada de los trabajadores del Distrito del Ministerio de Obras Públicas ${ }^{3}$, ubicado en la parte alta, en la salida hacia Villa de Leyva, a las 7:50 a.m. y a la 1:50 p.m. Esto marcaba también ritmos en mi casa. Al oír ese sonido mi mamá se aligeraba porque también le indicaba que debía salir a trabajar, era empleada en una oficina gubernamental. El otro era al amanecer: el tren tocaba su silbato en su paso hacia Bogotá y se sentía especialmente fuerte por la cercanía de la carrilera a la casa.

Cuando se habla de este periodo con familiares, amigos, conocidos, estos sonidos llegan a la memoria inmediatamente. Hacían parte del paisaje de la ciudad, entendido como el conjunto de sensaciones que lo construyen, fueron sonidos industriales, sonidos del trabajo que marcaron los ritmos de los hogares durante mucho tiempo. Mauricio

\footnotetext{
${ }^{3}$ El terreno donde se instaló el distrito del Ministerio de Obras Públicas (Ministerio de Transporte desde 1992) en un principio había sido destinado a la estación del ferrocarril del Carare, que fue el primer proyecto de tren que pasaría por Tunja. Su intención era buscar el río Magdalena, este proyecto no prosperó, lo que sí quedó fue el nombre del Carare que marcó este sector.
} 
Bejarano $^{4}$ habla de la importancia del sonido, que no se ha valorado suficientemente, y aunque existen las facilidades para capturarlo, de atraparlo, se sigue perdiendo; los tañidos de las campanas en el centro, el paso del tren, los electrodos descargando energía, las trituradoras de minerales, las plazas de mercado. Es el sonido de la vida, el sonido de los lugares, de las ciudades. Por su parte, Carlos Fortuna (2009) nos dice que:

Este relativismo sonoro habla incluso de nuestra experiencia social y biográfica, ya que tanto puede revelar una memoria y un pasado $y$, de este modo, una actividad vivida, como puede, igualmente, enunciar un estado de extrañamiento y disconformidad ante sonoridades desconocidas ( $\mathrm{y}$, en un extremo, ante sonoridades ausentes) que se pretenden descifrar en su significado o sentido abstracto. (p. 47)

Otros recuerdos han cobrado fuerza, uno de ellos era el del mercado. Este se distribuía de dos formas: uno, el de frutas y legumbres frescas, que lo hacía mi mamá en la plaza ${ }^{5}$ y el otro, era el de grano, como lo llamábamos, que nos correspondía a los hijos. Me mandaban a hacerlo al IDEMA (Instituto de Mercadeo Agropecuario), que mis hermanos mayores conocieron como el INA. Ahí, en unas grandes bodegas, adquiríamos a precios módicos, arroz, arvejas y frijoles secos, también se veían bultos de cebada y maíz. Al lado unas altas construcciones cilíndricas de metal que brillaban con el sol. Para llegar a este lugar, la buseta atravesaba una nube de polvo blanco; desde la ventana se veía todo cubierto por él, salía de las fábricas que escasamente se veían entre el humo y que se percibían más por el ruido que generaban. Lo que R. Murray Schafer llamó "bruma sonora" que envuelve los ambientes citadinos más densos. Se trata de una cacofonía, próxima a lo que consideramos ruido (Fortuna, 2009). Era el estruendo de la naturaleza obligada a transformarse. Ese paisaje contaminado no pasaba desapercibido.

\footnotetext{
${ }^{4}$ Mauricio Bejarano. Arquitecto de la Universidad Nacional, investigador y creador de música concreta, música acusmática, arte sonoro y paisaje sonoro. Estudió composición electroacústica en Francia.

${ }^{5}$ Cuando Tunja cumplió 400 años de su fundación hispánica en 1939, se inauguraron tres edificios emblemáticos: la Plaza de Mercado, hoy monumento nacional y además centro comercial y administrativo, el mercado fue trasladado al sur de la ciudad. Los otros dos son la Estación del Ferrocarril y el Batallón Bolívar.
} 


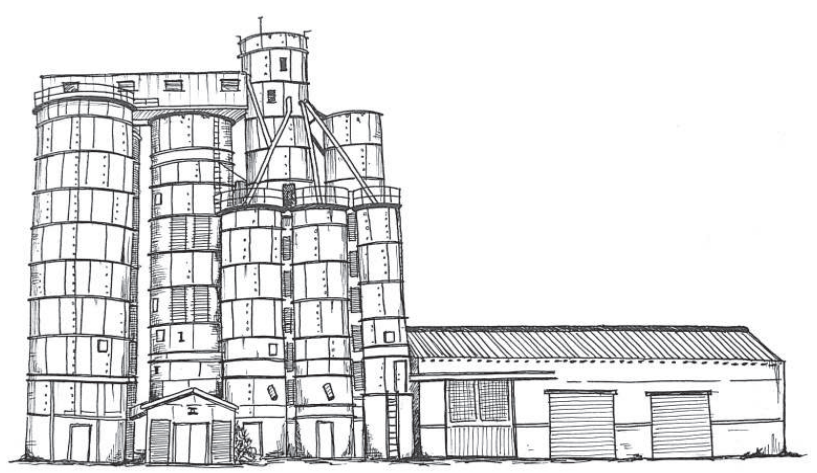

Imagen 3. Silos del Idema. Fuente: Jeikson Orjuela.

Aunque transcurran años es imposible desligar lo sucedido aquí de lo ocurrido mundialmente en cuanto a los procesos de industrialización derivados de la Revolución Industrial. En proporciones modestas se repiten ciertos fenómenos; se pasa de comunidades campesinas a comunidades obreras. Los sectores fabriles se construyen lejos de los centros urbanos, y se van conformando en sus entornos, unos centros habitacionales que facilitan los desplazamientos de los obreros conocidos como "Company Towns", lugar en el que se consolidan los barrios. La Revolución Industrial marcó profundamente la historia de la humanidad y de la misma manera es conocida la influencia y el cambio que ella significó en la economía: el progreso, avances tecnológicos, fuentes de trabajo, con todos los problemas de explotación de obreros y mineros.

Desde finales de los sesenta y hacia los ochenta, se dieron grandes cambios en la economía mundial; el trabajo organizado, las cargas impositivas y la naciente legislación ambiental hicieron que las grandes empresas miraran a los países de la periferia. En ellos,

la destrucción de la pequeña producción campesina, entre otros por la modernización del campo, así como varios otros factores (control sindical, militarización del poder civil, apoyo exclusivo a las ciudades, etc.) han contribuido a crear una enorme reserva de mano de obra desocupada, permanente, y en consecuencia barata. (Hiernaux, 1981, p. 20) 
Estos aspectos se venían desarrollando en Colombia. Capitales locales en la incipiente industrialización, la participación del Estado y una falta de experiencia tanto de los dueños como de los trabajadores, no permiten que el proceso se consolide a largo plazo.

El sector industrial de Tunja está delimitado por el paso a nivel del barrio Mesopotamia, abriéndose paso entre el río Jordán y la carretera central del norte, tomando la antigua salida a Paipa y cierra a la altura de la plaza de mercado del norte, donde se acercan la carretera y el río. Hacia el occidente de esta planada se empieza a elevar una colina y, hacia el oriente, al otro lado del río, eran los humedales. Sector reconocido en el plan de ordenamiento territorial de 1958, conocido como "plan piloto" y que tendría una implantación hasta 1985, como sector de la industria pesada. Este terreno era ideal para construir, pues no requería ni excavación ni relleno. Con el tiempo, los humedales empezaron a ser rellenados, la ciudad no ha implementado políticas para su protección, el actual Plan de Ordenamiento Territorial escasamente los menciona. Se podría decir que ya se perdieron o desaparecieron.

La estación del tren de Tunja es la más antigua y la única que conserva su función original. Ahora se ve más bien modesta, aloja solo oficinas, es un edificio con tintes art déco en su fachada. Cuando estaba en su apogeo, contaba con instalaciones de bodegaje, espacios para alojar trabajadores, depósitos y embarcadero de ganado. Todo esto se ha venido derrumbando por su abandono e inutilización. Por encontrarse frente a una universidad pública, la Universidad Pedagógica y Tecnológica de Colombia (UPTC), su significado trasciende su función, cuando hay protestas estudiantiles se convierte en barricada de la policía; y además sus paredes se utilizan como lienzo de todo tipo de grafitis, como cualquier edificio dentro de la universidad. Es de las pocas estaciones que sigue en función del ferrocarril ${ }^{6}$. Este se ha conservado activo como tren de carga, el transporte de pasajeros dejó de funcionar en los años sesenta. El tren estuvo inactivo un tiempo debido a las fuertes inundaciones de 2012, y que arrasaron con parte de la vía. Ahora, nuevamente, se empieza a escuchar su estruendoso silbido - sigue siendo fuerte- apabullando no solo el sonido de los carros, sino llamando la atención con su imponente presencia.

\footnotetext{
${ }^{6}$ Las estaciones del tren fueron declaradas BIC, Decreto 746 del 24 de abril de 1996. En un intento por evitar que las estaciones siguieran siendo demolidas y sus terrenos usados para otros fines. Algunas han desparecido y otras siguen ese proceso, otras han sido rescatadas y su función cambia, como la estación del sur de Tunja, fue la estación de pasajeros, que ahora es la sede de la policía de tránsito. En gran parte del país el tren ha dejado de funcionar, cuando esto sucede estas edificaciones por lo general se destinan a centros culturales.
} 


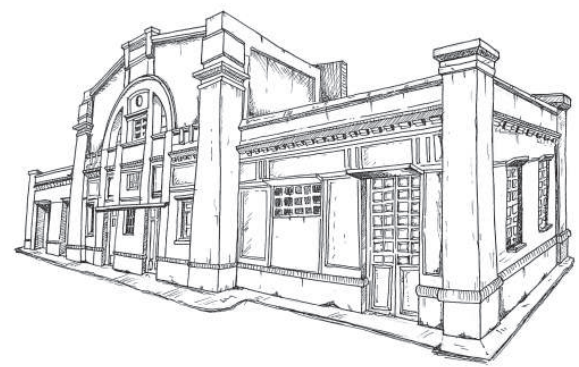

Imagen 4. Estación Norte Ferrocarril del Nordeste. Fuente: Jeikson Orjuela.

Más al norte, a pocos metros de donde el río Farfacá y el río Jordán se unen, se encuentra el terreno de las dos empresas que generaban el humo blanco que cubría todo: Caolines Boyacá y Ferroaleaciones de Colombia. Empresas que se crean a finales de los sesenta y en las que se desarrollaban factorías de productos intermedios, por un lado, una procesadora de cal y, por el otro, especialmente de carburo. Las dos empresas eran de carácter privado. Caolines fue obligada a trasladarse a otro lugar por los altos índices de contaminación que generaba. Esta factoría desapareció totalmente $\mathrm{y}$, en el terreno que ocupaba, ahora se encuentra un centro comercial. Ferroaleaciones, además de los motivos contaminantes, también deja de funcionar por asuntos administrativos. A finales de los años 90, cesan completamente sus labores, se encuentra abandonada, en ruinas, con un deterioro cada vez más acelerado, sus chimeneas metálicas aún se sostienen sobre las ruinas blancas de su edificación, estas permanecen aún como un referente de ubicación.

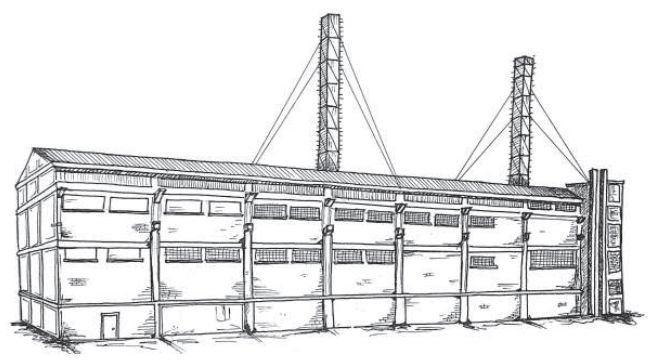

Imagen 5. Minera y Ferroaleaciones de Colombia. Fuente: Jeikson Orjuela. 
La subestación de energía de la Electrificadora de Boyacá que atendía el requerimiento eléctrico de la ciudad funcionó algunos años. La demanda de la ciudad creció y prontamente la dejó obsoleta, la Empresa de Energía de Boyacá se había involucrado en el proyecto de Termopaipa que ahora suministraba la energía a Tunja. El edificio fue abandonado, mas no el terreno, ya que era de grandes extensiones, lugar en el que actualmente se encuentran instaladas las bodegas de la empresa, que además ha pasado a ser propiedad privada. La enunciación optimista del plan piloto de 1958 como el sector de la industria pesada, a finales del siglo XX se había convertido en un territorio yermo, desolado. La ciudad continuaría creciendo a su alrededor.

En 2005, estábamos embarcados, con otros dos compañeros y unos estudiantes, en un proyecto de paisaje. En ese momento, no teníamos la intención de puntualizarlo en lo industrial, aunque todo apuntaba a que así sería. Conseguimos que nos prestaran el edificio abandonado para mostrar los resultados de nuestro trabajo. Solo existía el cascarón que albergó la generadora de energía: la nave principal, un cubo de unos 20 metros de lado, hecho en ladrillo y columnas de hormigón, con grandes ventanales por los que la luz entraba en abundancia, los soportes de la maquinaria, robustos bloques con toda la apariencia de un búnker, y una nave más pequeña que albergó transformadores y algunos espacios administrativos. Nuestro trabajo consistía en una instalación de video y sonido de un viaje en tren que habíamos hecho desde Sogamoso a Paz de Río, un pueblo cercano a la acería. Desde ese tiempo existía el proyecto de rehabilitar el edificio para dar lugar al centro de servicios de la entidad y que funciona actualmente allí.

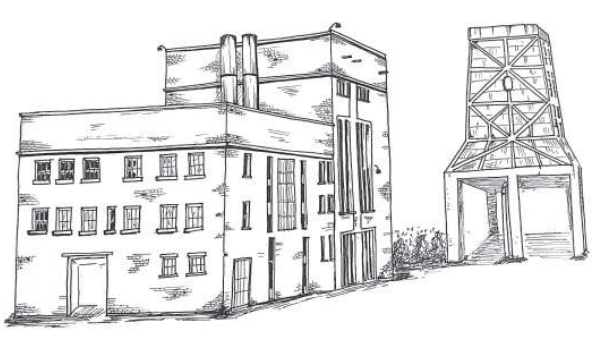

Imagen 6. Subestación de Energía de Boyacá. Fuente: Jeikson Orjuela

Marcando el límite norte de este paisaje se encontraban los silos del IDEMA como yo los conocí, anteriormente el INA (Instituto Nacional de Abastecimiento). Estaba conformado por once silos metálicos con una altura de un edificio de seis pisos y una bodega que también había sido 
referente de una zona "muy" al norte de la ciudad. Después de haber sido un proyecto gubernamental de gran envergadura y que tuvo origen en el Frente Nacional ${ }^{7}$, con la intención de regular precios de los cereales, dejaron de funcionar en los años 80. Estuvieron abandonados por una larga temporada, razón por la cual pasaron a ser propiedad del municipio. La bodega fue prestada a los skaters, como un lugar transitorio para su práctica: los muchachos llamaron a su club "La industria". Tuve la oportunidad de ingresar a los silos en 2015, en los últimos días de práctica del skate en la bodega que les habían asignado. Eran grandes cilindros de láminas de aluminio ensamblado con tornillería. Adentro había escaleras verticales que llevaban a la cima, contaba con tubos que comunicaban un silo con otro, bandas transportadoras, sistemas de carga, ventiladores. El sonido producido por los granos al pasar de un silo a otro, al cargar los camiones, tuvo que ser maravilloso. A las pocas semanas empezó su desmontaje.

Resulta imposible pensar en la industria sin sus ruidos de maquinaria, de transporte, de obreros levantando la voz para hacerse oír, de sirenas y pitos. Ahora, todas las máquinas han quedado silenciadas. Este conjunto de empresas marcó e impulsó el crecimiento de la ciudad. Dos de ellas, Caolines y los silos han desaparecido. La subestación cambió su función. Ferroaleaciones está abandonada, en ruinas, y la estación del tren apenas pervive. El ruido pareciera haberse salido a las calles, ahora producido por la cantidad de vehículos que transitan por la carretera que siempre ha bordeado el sector.

Tunja empezó a cambiar también. El crecimiento poblacional se aceleró, el sector al norte de la ciudad se convirtió en uno de los más populosos $\mathrm{y}$, naturalmente, hubo un crecimiento del transporte. Surgen en el sector los planes de vivienda formal, tanto de proyectos gubernamentales como privados. Se pasa de una universidad a tres y las empresas de servicios se instalan en el área.

Voy cámara en mano intentando capturar imágenes, antes de que todo esto quede en recuerdo y de ahí se desvanezca - seguramente la primera que se diluirá será Caolines Boyacá-. No hay rastros, las personas mayores se sorprenden cuando se les pregunta por esta empresa, hasta en la memoria quedó reducida a un rincón. Los silos del IDEMA seguirán la misma suerte en poco tiempo al haber sido

\footnotetext{
${ }^{7}$ El Frente Nacional (1958-1974) es una etapa de la historia de Colombia, generada por la problemática de violencia entre los dos partidos existentes en ese momento, el liberal y el conservador. Se llegó al acuerdo de que la presidencia de la Republica se turnaría entre partidos. Esto con la intención de acabar con la guerra partidista.
} 
desmontados. Con el registro de las imágenes intentaba comprender cómo funcionaban, qué recorridos hacían los granos al pasar de un silo a otro, pasando compuertas, llenando los ductos, buscando las salidas, que permitirían cargar nuevamente a los camiones completando su ciclo vital al ir a los mercados nuevamente. Intentaba imaginar el sonido del fluir del grano, los motores en marcha de los camiones y las charlas de los choferes con los funcionarios de la empresa.

Ferroaleaciones es un paisaje de deterioro, destrucción y abandono. Eso que el arquitecto Kevin Lynch denomina bordes que son los límites entre dos fases o rupturas lineales de la continuidad. El terreno se encuentra cercado con un muro de piedra y ladrillo, un interior oculto, la maquinaria se va oxidando lentamente, y poco a poco va desapareciendo en procesos de chatarrización. En la estructura, varillas de hierro ya están a la vista, el hormigón carcomido, los ductos ya no protegen el cableado. Por los canales ya no fluyen materiales, ahora albergan aguas estancadas. Los techos ya no existen y el edificio ha sido invadido por las palomas que miran sorprendidas a ese intruso armado con una cámara. El referente de la subestación de energía también se va perdiendo y prevalece el de centro de servicios.

La desaparición de las industrias parece ser inevitable y en su lugar quedarán algunos de los registros de lo que allí sucedió. Los obreros y trabajadores han cambiado de lugar o han fallecido, quedan pocos, cada vez son más endebles los recuerdos. Desde que empezaron a emerger estas empresas en el sector prevalece un espíritu de trabajo, en el sentido que es la principal actividad que se puede apreciar en ese entorno que ha marcado este territorio. En los barrios vecinos, Santa Rita y La Granja, se han dado en gran parte por procesos de autoconstrucción, donde las casas han sido edificadas de acuerdo con las posibilidades de sus propietarios, lentamente, habitadas desde lo que se conoce como obra negra; es decir, escasamente paredes y techo, con una particularidad enunciada ya por Ricardo Toledo Castellanos $^{8}$, pero con una intención mucho más clara en que el primer piso de las construcciones estarían destinados a lugares de trabajo, unos primeros pisos casi a doble altura pues allí funcionarían talleres, bodegas, lavanderías y encima de ellas lugares de habitación. Los restaurantes del sector, alguna vez para obreros, se han tornado tradicionales de la cocina tunjana y punto de referencia para toda la ciudad.

\footnotetext{
${ }^{8}$ Ricardo Toledo Castellanos, Artista teórico, hace un estudio de los procesos de autoconstrucción y comparte su reflexión en el texto "Resistencia y esperanza, las fuerzas que fundan un hogar".
} 
Otro de los barrios, el llamado José Joaquín Camacho, tomó otra forma. En sus inicios, algunos obreros adquirieron los lotes, asumiendo procesos de autoconstrucción. Con el transcurrir del tiempo sus hijos se van haciendo profesionales, las viviendas se tornan multifamiliares, el barrio toma tintes residenciales y se llena de edificios de apartamentos. Esto también ocurre, posiblemente, por el terreno del barrio que es ya una ladera más inclinada. Hay otro contexto barrial que vale la pena mencionar: Las Quintas, que surge después de que las empresas habían cesado sus labores. Se construye al otro lado del río, sobre los rellenos de los humedales, por la parte posterior de las edificaciones industriales. Construcciones que al estar abandonadas por mucho tiempo, permitieron que el sector se convirtiera en un lugar inseguro para transitar y que era de paso obligatorio para sus residentes. Aún hoy en el imaginario de sus habitantes, estratificado más alto ${ }^{9}$, es el de inseguridad y al que no hay que acercarse.

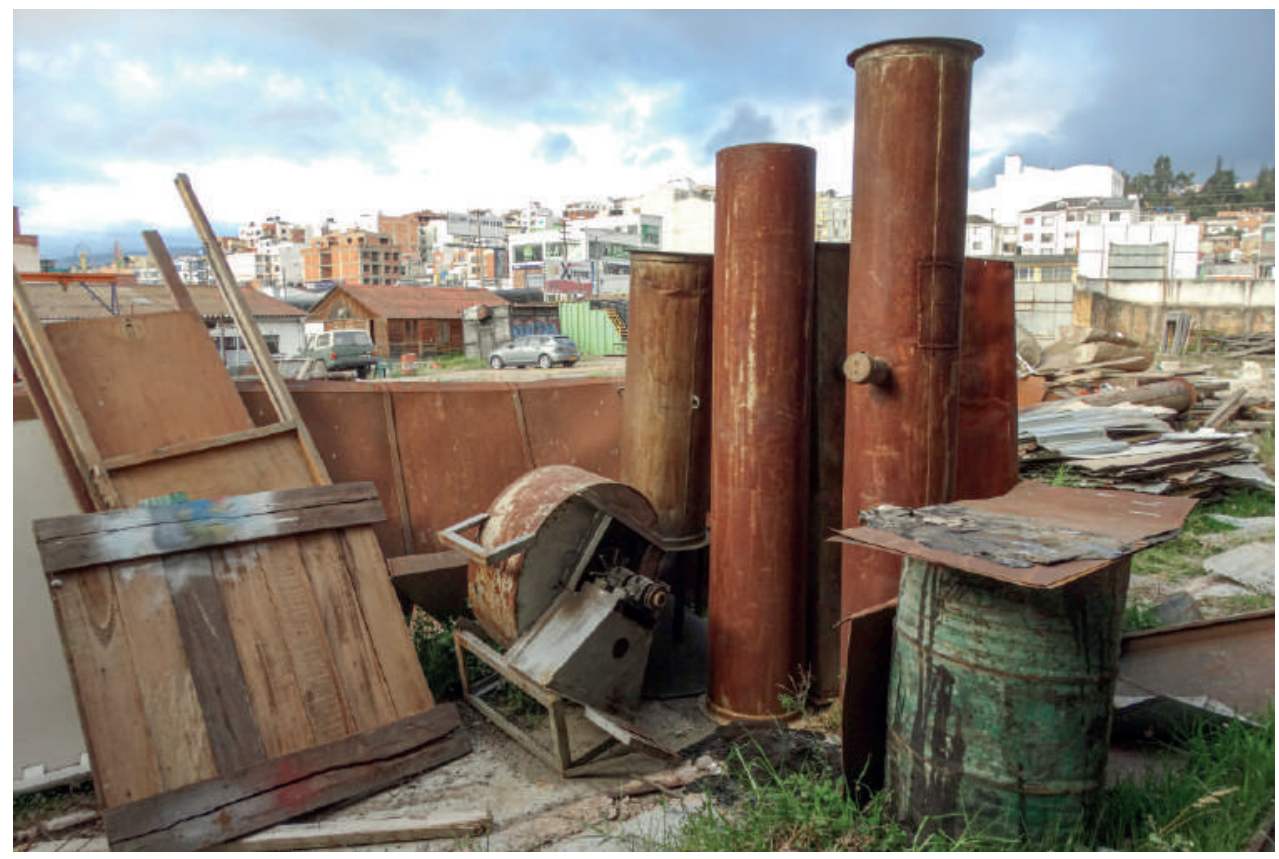

Imagen 7. Ruinas Ferroaleaciones de Colombia. Vista hacia el barrio José Joaquín Camacho. Fuente: Autor (2017).

\footnotetext{
${ }^{9}$ La estratificación del espacio construido en Colombia se realiza para el cobro diferencial de servicios públicos especialmente, se hace una identificación geográfica de sectores con diferentes características socioeconómicas y permiten también tomar decisiones en la planeación y ordenamiento territorial de las ciudades. Los estratos están diferenciados entre 1 el más pobre a 6 el más pudiente. El barrio mencionado está catalogado como 5, los otros enunciados pertenecen a las categorías 3 y 4 .
}

94 | antropol.sociol. Vol. 21 No. 2, julio - diciembre 2019, págs. 81-101 | 
La carretera también cambió. Cuando las empresas comenzaron sus actividades, la vía que conducía al norte y bordeaba inicialmente el sector, era de un solo carril. Ahora es doble calzada y hacia el norte cambió su trazado hacia Paipa. La anterior bordeaba la ladera. Esta, pasa por encima. Al ser una de las vías principales de la ciudad, también florecen a sus lados empresas prestadoras de salud, clínicas, concesionarios de autos nuevos y usados, centros comerciales, y otros establecimientos pequeños, papelerías, discotecas, bares.

En Europa y Norteamérica quedaron inmensas factorías abandonadas que empezaron a ser demolidas; la arquitectura industrial, caracterizada por ser un tipo de construcciones que exigían un estilo diferente, parecido a las catedrales, tanto en altura como en áreas protegidas, particularmente sin los adornos de un lugar sagrado y con una cantidad de luz y la capacidad de albergar los procesos propios de lo mecanizado y del ensamblaje, de las líneas de producción, precisa en su función, en sus estructuras, en el uso de materiales nuevos como el hormigón y el acero. Un estilo que también permeó la arquitectura de otros edificios no necesariamente industriales, como hospitales, puentes, edificios de oficinas y monumentos. No se creó con la intención de trascender en el tiempo, como los palacios y templos, sino para uso puntual. Estas características configuran un estilo que empezó a estudiarse tal vez por su inminente desaparición. Y si bien en Inglaterra es donde se va formando la conciencia de conservar estas construcciones que marcaron un importante periodo en la historia de la sociedad, el fenómeno se extiende a otros países, dando origen al Comité Internacional para la Conservación del Patrimonio Industrial (TIICHI) ${ }^{10}$ (por sus iniciales en inglés), que empieza a estudiar especializadamente los aspectos que constituyen este tipo de patrimonio.

\footnotetext{
${ }^{10} \mathrm{TIICIH}$ (The International Committee for the Conservation of the Industrial Heritage). Organización fundada en 1973. Consultor del Patrimonio Mundial de la Humanidad del Consejo Internacional para la conservación y la restauración de monumentos y sitios (ICOMOS) de la Unesco, para la selección de los monumentos, sitios y paisajes de la industria y de la industrialización y así incluirlos en la lista del patrimonio.
} 


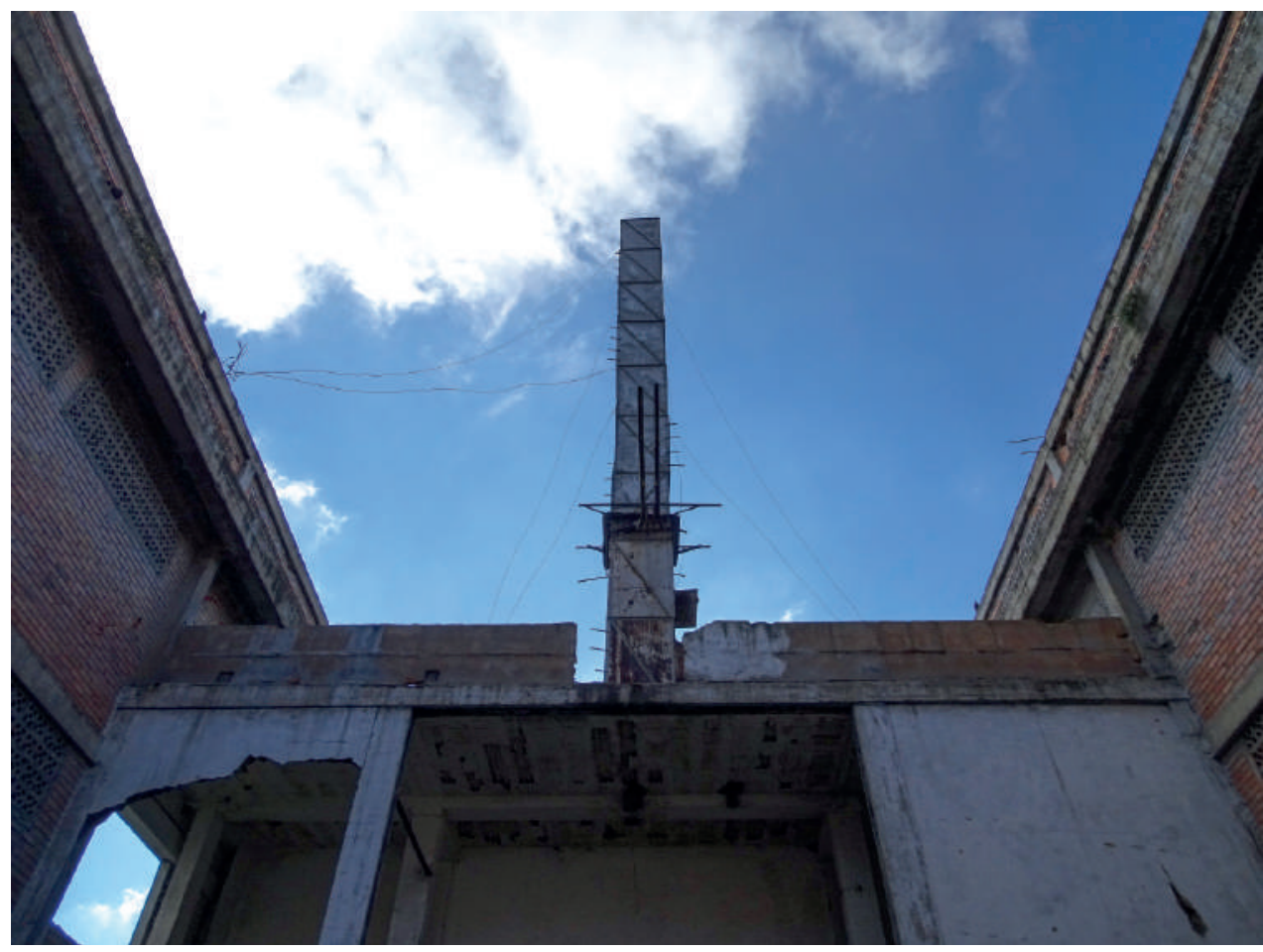

Imagen 8. Ruinas de Ferroaleaciones de Colombia, vista de una de las chimeneas. Fuente: Autor (2016)

Durante un periodo significativo, ciencia, técnica e industria pensaban y actuaban con base en estos mismos paradigmas. Sencillez de sus elementos constitutivos, a unas relaciones causa-efecto. Para Inmaculada Aguilar (2005), en arquitectura estos modelos de pensamiento nos hablan de funcionalidad, de racionalidad, de transparencia y de sinceridad en el arte de la construcción.

Esta arquitectura que se ha venido desvaneciendo en Tunja, no se oculta con mampostería, todo está a la vista, se comprende inmediatamente la forma como fue levantada, casi se puede ver el plano del proyecto, la estructura, sus amarres, los ductos conductores de energía, de aire, todo es de fácil percepción y su razón de ser hace necesario que así sea. El ensamblaje de los cascarones es evidente, hecho con tornillería que recuerda permanentemente su carácter efímero, posiblemente porque las exigencias de la factoría las harían cambiar de lugar o desaparecer definitivamente. Una arquitectura transparente y efímera, que permitiera su fácil ampliación o su desensamblaje, como en efecto ocurrió. 


\section{Arte y patrimonio}

El arte tiene que ver con la vida, con la comprensión íntima de los espacios vitales; con provocar actos de creación, de relación, de aprehensión del mundo insertando huellas que lo amplían, restituyendo el mundo de alguna manera; arquitectura, música, literatura, artes plásticas, audiovisuales, etc. Eso que se conforma en una suerte de identificación, de lo hecho por la humanidad, y no solo en el sentido de producirlo sino también de habitarlo, de escucharlo, de leerlo, de verlo. Lo que Gilles Deleuze (2005)llama acontecimiento que, a diferencia del suceso, hace que en él se conjuguen todos los tiempos, un sin-tiempo, un espacio mental. Es el momento en que se sale de lo rutinario, de lo cotidiano y se instala en el borde y se hace conciencia de su existencia. Podríamos pensar que es lo que sucede con el patrimonio, eso que nos identifica, que en cierto sentido nos da soporte, nos permite asirnos en esos momentos en que el sentido tambalea.

Así, si se toma lo enunciado por Deleuze (2005) "lo que debe ser comprendido, lo que debe ser querido, lo que debe ser representado en lo que sucede" (p. 183). Entonces se vuelve vital entender este territorio que habito desde siempre; que se ha ido formando en el tiempo, en la imaginación, en los sucesos, en lo recorrido, todo acumulado en la memoria (el acontecimiento) configurando lo que soy y a quienes compartimos el habitar de esta ciudad, que hemos tenido historias, vivencias comunes, experiencias nacidas en ese territorio cambiante, es decir un sentido patrimonial.

Las relaciones del patrimonio y el arte se hacen necesarias, se fortalecen, como provocadores mutuos; "el arte conserva, y es lo único en el mundo que se conserva. Conserva y se conserva en sí. Aunque de hecho no dure más que su soporte y sus materiales" (Deleuze y Guattari, 2001 p.164). Permite encontrar lo oculto, o lo que no se sabía que se había ocultado y que el arte guarda en sí, así no sea evidente. Permite ponerlo en presente y hacerlo significativo. Así, el arte en sentido que venimos trabajando, también podría ser un estado de encuentro, un acontecimiento; un lugar, unas imágenes, unos sonidos con rastros que permiten el recuerdo, permiten la posibilidad.

Es también una potencia del patrimonio pensado como lo que permite tener experiencias comunes: "el monumento no conmemora, no honra algo que ocurrió, sino que susurra el oído del porvenir las sensaciones persistentes que encarnan el acontecimiento" (Deleuze y Guattari, 2001, p. 178). Si el monumento desaparece queda el silencio. Se pierde lo que permite la conjunción. La función del patrimonio estaría en poner en 
presente, en presentar para evitar el olvido, "desocultar" lo existido y olvidado. Así el patrimonio "monumenta", permite que continúe el susurro. Entonces el arte también puede ayudar a "monumentar" al enunciar en sus imágenes aquello que aún está o que estuvo.

Esta herencia, este sector industrial, se puede concebir como un objeto productor de lo social en cuanto a que permitió la identificación. Una producción de relaciones con el mundo mediado por una serie de objetos y de prácticas específicas (De Certeau, 1999) conocidas o intuidas. Ocurridas en un territorio en el que aún persisten de otras formas: transformación de materiales, relaciones laborales. Obreros, mineros, cultivadores, transportadores, comerciantes siguen siendo sinónimos de la idiosincrasia de los habitantes de esta región. Un sentido del patrimonio es no dejar que se pierdan.

Si retomamos el arte como creación y el patrimonio como conservación, su mutua relación se evidencia. El arte amplia el sentido patrimonial, acentuando su poder de generador de procesos creativos, dejando de lado su preconcebido anquilosamiento. Así, también se da una ampliación de lo que lo constituye, actualizándolo permanentemente. El arte posibilita acontecimientos.

Como enuncié arriba voy recorriendo esos lugares abandonados. Espacios silenciosos, con el tiempo detenido, son como fotografías que se recorren, como si esperaran a quedar atrapadas en la cámara para ser nombradas. En palabras de Giorgio Agamben, exigen un nombre, exigen no ser olvidados. Nombrar permite su entrada en la cultura, anuncia su existencia. En el mismo sentido:

También para mí la exigencia que nos interpela a través de las fotografías no tiene nada de estético. Es, sobre todo, una exigencia de redención. La imagen fotográfica es más que una imagen: es el lugar de un descarte, de una laceración sublime entre lo sensible y lo inteligible, entre la copia y la realidad, entre el recuerdo y la esperanza. (Agamben, 2005, p. 27)

Con la fotografía intento atrapar un tiempo indefinible de eso que fue fuego, fue ruido, fue fuerza, fue trabajo, fue sustento, fueron familias y sueños, ahora convertidos en desechos y ruinas que quedan atrapadas en imágenes que no evidencian nada; pero que están ahí, presentes, inmersas y que son enunciadas en esa imagen detenida. Por eso hay que nombrarlas, hay que restaurarlas en la memoria, en el documento, en el relato. 


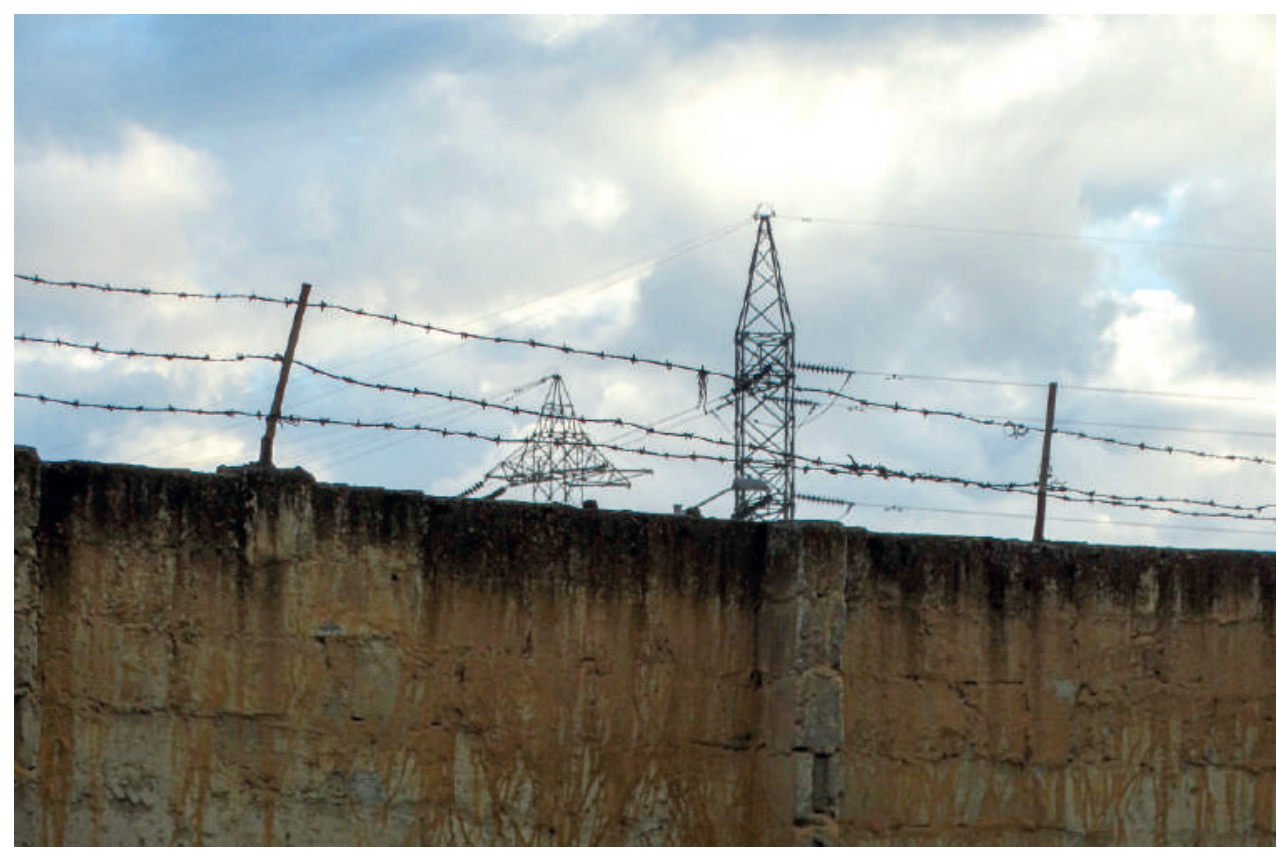

Figura 9. Muro en ruinas entre Ferroaleaciones de Colombia y la Empresa de Energía de Boyacá. Fuente: Autor (2016)

Es un sentido que he encontrado al tomar fotografías en la ciudad: también se protege una herencia citadina. Cuando me doy a la tarea de fotografiar las fachadas de las casas y edificios, cuando se enfoca la cámara en esos lugares llenos de transeúntes, la gente mira hacia donde uno enfoca, salen de sus recorridos habituales para darse cuenta por sí solos de esos instantes, de esos otros lugares en los que posiblemente no se habían fijado anteriormente y que pasan desapercibidos. Enfocar con la cámara también es proponer un espacio estético, es una experiencia extendida, posibilitada por un instante de captura de la imagen.

Al fotografiar estos espacios industriales ya no hay testigos, han sido cerrados y nadie volvió a entrar en ellos, se volvieron indiferentes: detrás de un muro o de una cadena y un candado, pudriéndose y oxidándose, inaccesibles. Hay que entrar subrepticiamente, fuera de la mirada cotidiana: "la ruina moderna ha perdido su nobleza, no obedece al paso del tiempo ni nos recuerda eventos pretéritos. Esta situación ha provocado un acelerado cambio en los procesos de asimilación simbólica de los acontecimientos" (Monsalve, 2015, p. 68). 
Unas ruinas a destiempo. La ruina industrial no tiene esa nobleza de la que habla Margarita Monsalve, son desechos de un esfuerzo que además es tardío, las ruinas "son testigos de lo efímero e inocuo del esfuerzo humano y ambición desmedida. De esta forma son portadoras de una visión distópica" (Monsalve, 2015, p. 68). Las ruinas industriales no hacen remembranza de momentos históricos particularmente gloriosos o dolorosos como los misterios del rosario. Más bien hacen pensar en lo cotidiano, en lo rutinario, en la lucha diaria por ganar un sustento que permita continuar con la existencia. Como lo expresa Monsalve (2015):

Las ruinas sirven como recordatorio. La memoria siempre es incompleta, siempre imperfecta, siempre está convirtiéndose en ruina. Aun mas, las ruinas mismas son nexos con lo que vino antes, nuestra guía para situarnos en un paisaje de tiempo. Borrar las ruinas es borrar los mecanismos públicos para desencadenar la memoria, y una ciudad sin ruinas y rasgos de edad, es como una mente sin memoria. (p. 94)

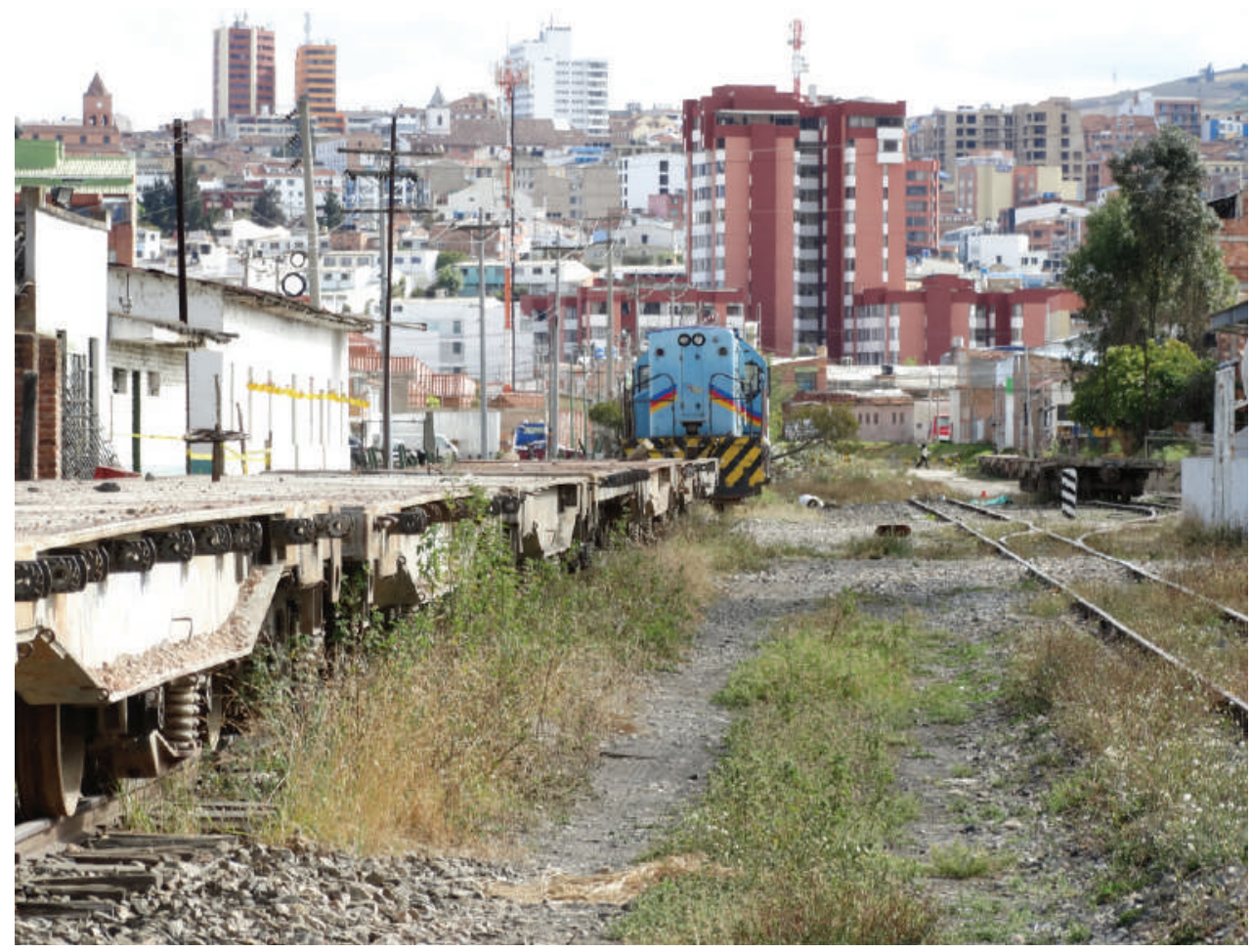

Figura 10. Vista desde la Estación del Ferrocarril al centro de la ciudad. Fuente: Autor (2014). 
Camino por la carrilera, el lado más oculto, más olvidado, la franja posterior a las fábricas; desvíos de la carrilera casi desaparecidos, ocultos, oxidados, cubiertos por la maleza, que accedieron hace años a las empresas. Los durmientes de madera de los rieles que ya no serán usados esperan perfectamente encarrilados convertirse en abono de la enredadera, de persistentes bichos capaces de alimentarse de madera inmunizada. Vigas de hierro oxidado, postes de energía desconectados; sus cables ahora son sostén de líquenes. Plantas de curuba (Passiflora) trepan el muro se asoman a la calle, intentando escapar del olvido, enredándose en los alambres que pretenden proteger un lugar abandonado.

Hay que hacerlo lentamente, el andar. Adaptar el paso a la distancia de los durmientes, ahora de concreto. El murmullo de los carros se escucha en la distancia, el río pasa silencioso, pesado, lento, contaminado. Carretera, carrilera, río... Este es un paisaje de abandono, melancólico: las arrugas de la ciudad.

\section{Referencias bibliográficas}

Agamben, G. (2005). Profanaciones. Buenos Aires: Editorial Adriana Hidalgo.

Aguilar, I. (2005). La arquitectura industrial en la obra de Demetrio Ribes. Hacia una arquitectura racionalista. Fabrikart (5).

Calvino, I. (1999). Las ciudades invisibles. Madrid: Siruela.

De Certeau, M. (1999). La invención de lo cotidiano. México: Universidad Iberoamericana.

Deleuze, G. (2005). Lógica del Sentido. Barcelona: Paidós

Deleuze, G y Guattari F. (2001). ¿Qué es la Filosofía? Barcelona. Editorial: Anagrama.

Fortuna, C. (2009). La ciudad de los sonidos. Una heurística de la sensibilidad en los paisajes urbanos contemporáneos. Cuadernos de Antropología Social, (30), 39-58.

Hiernaux, D. (1982). Industrialización portuaria, desarrollo económico y cambio espacial en México. Los grandes complejos industriales y su impacto en el espacio latinoamericano. México: Instituto de Geografía de México.

Kueva, F. [FabianoKueva]. (26 de enero de 2018). DIALOGO \#4: MAURICIO BEJARANO (compositor colombiano) [Archivo de video]. Recuperado de https://www.youtube.com/ watch? $\mathrm{v}=\mathrm{SuKm}$ t283Uts.

Lynch, K. (2015). La imagen de la ciudad. Barcelona: Gustavo Gili

Monsalve, M. (2015). Ruina, espacio y tiempo en las narrativas visuales. Bogotá: Universidad Nacional de Colombia.

Toledo, R. (2013). Resistencia y esperanza, las fuerzas que fundan un hogar. Cuadernos de Música, Artes Visuales y Artes Escénicas, 8(2), 17-48. 